\title{
Euro Skepticism and Right Wing Populism
}

\author{
Zhanna Dossan \\ $\mathrm{PhD}$ (Candidate), School of Political Science and Public Administration, Wuhan University, \\ Wuhan, Hubei, 430072 China
}

\begin{abstract}
Euro Scepticism and Right Wing Populism are two similar phenomena in recent times because new parties are constantly coming up with new challenges. It was observed that multiple crises took place in European context, which had a major influence on the development of new parties in both Euro Scepticism and Right Wing Populism. This research aimed to investigate the reasons behind downfall of Euro Scepticism and Right Wing Populism parties. For that reason, critical literature review method was adopted to investigate the influence of debt crisis and refugee crisis on the parties. The results were based on research articles lying in the last 5 period. The results obtained show that this cleavage is running in inclusive and exclusive European cosmopolite, which is the main reason behind this lack of votes.
\end{abstract}

Keywords: Eurosceptism, right wing populism

DOI: $10.7176 /$ IAGS/78-03

Publication date: December $31^{\text {st }} 2019$

\section{Introduction}

Right-wing populism and national populism are considered the political ideologies, which are based on the combination of right wing-politics and populist rhetoric themes. In Europe, this term, named populism is a term used for defining the groups, political parties and politicians, who are generally known for opposing to immigration (Petsinis 2019). Especially, in Europe, this term is named as the one revolving around the Islamic world, because it is against the Muslims. Traditional Euro Scepticism and Right Wing Populism are depending on the development of anti-Muslim immigration principles and policies. In the last few years, it has been observed that a surge of political polarisation took place, especially in the USA, where a high number of political laws for anti-terrorism were deployed against the Muslims.

This increased polarization is also due to the involvement of other member states of European Union (EU). It is believed that this increase in Euro Scepticism and Right Wing Populism is because of the uptick in both leftwing and right-wing figures and political parties, which shifted the political agenda both supranational and nationally (Shein 2019). In addition, it is observed that special concerns have been put forward by far-political right influence in the EU. Although populism does not constitute on a new phenomenon in recent times, success of old ones and proliferation of new populist parties are bringing a renewed attention of the parties. Especially in Europe, it has been observed that debate on newly emerging populism has been related to thread of academic attention, titled Euroscepticism.

Both the concept Euro Scepticism and Right Wing Populism are not similar on some occasions, however, their frameworks and objectives are more or less similar to each other (Petsinis 2019). Supporting the statement, Shein (2019) argued that Eurosceptic parties are not meeting populist features, such as LCS in Lithuania, SAS in Slovakia, ODS in Czech, and also the British Conservatives. However, it is observed that the performance of the companies in the current renaissance of populism in Europe has shown obvious correlation between Euro Scepticism and Right Wing Populism. Because the current renaissance of Europe has shown that parties involving in old parties have increased their Eurosceptic appeal.

The older Euroscepticism concept showed that their approach was found towards the development of antiEuropean stance, which was advocated towards leaving the Economic and Monetary Union. This development shows that populism is coming under a moving target and supply side should be made flexible according to new circumstances, hence awards like Euroscepticism have increased (Ibid: 05). Therefore, there is a need to take notice of this quality change, and linking the populism with Euroscepticism to have a closer change on them.

\subsection{Problem statement}

There is limited research done on this topic of populism, especially in two research areas namely Euro Scepticism and Right Wing Populism. According to the findings of Evans and Mellon (2019), the developments in both these concepts have taken place rapidly especially in theoretical concepts and robust empirical findings, it is believed that they run in parallel functions, due to which there is a limited cross-fertilisation in these theories and empirical findings. The study of Evans and Mellon (2019) further argued that research done on Euroscepticism is depending on 3 theoretical explanations, which include the economic factors and economic performance which include (inflation, unemployment and economic growth). While another study argued that it is depending on the identity factors, which steam from attitude of how Europeans are conceiving their identities 
(Stengel, MacDonald and Nabers 2019). These factors include civic versus ethnic and exclusive vs inclusive (Ibid: 06). In addition, the distrust towards national and European institutions is also reported. Therefore, there is a need to remove this disparity of information in available literature.

The aim of this research paper is to look into a recent upsurge in Euro Scepticism and Right Wing Populism by observing their relationship and frameworks. The research of Stengel, MacDonald and Nabers (2019) it should be assumed that multiple crises have been experienced in the last decade, which had a major influence on the populist and Eurosceptic parties. For example, Hooghe and Marks (2007) have considered crisis as a critical juncture and even, when it ushered a new era. They argued that this critical juncture will be producing a new cleavage, which includes a transnational cleavage. In this cleavage, the parties settle down along the poles, which stand for their protection of national values, and to defend the national sovereignty. In addition, the issues of global trade and immigration have also been addressed by these parties for the development of new legislations. Therefore, this research paper aims to work on the following questions:

1. What are the overlaps in the concepts of Euro Scepticism and Right Wing Populism, which should be known to people?

2. Which are the famous Euro Scepticism and Right Wing Populism parties operating in the European Region?

\section{Method}

This part of the research paper describes a portion of the necessary headings required for the examination in this investigation. For that reason, this part of the paper is partitioned into a few headings to describe the strategy chosen for examination. Research method or strategy alludes to choosing the best strategies for examination and giving the outcomes in a sufficient way. Research strategies and methods must be chosen in a way that best answers the inquiries and points of an examination (Cuervo-Cazurra et al., 2017). The following part of the paper gives the comprehension of the ideas chosen for the examination alongside the devices which have been utilized for introducing the outcomes.

\subsection{Research context}

The research context clarifies the techniques, and nature of strategies chose for a study. After understanding the context heading, it gets simpler for a student to comprehend what kind of contentions would come in the forthcoming headings (Ramirez et al., 2015). This exploration is relying upon quantitative and qualitative research context since it attempts to clarify the suggestions which can be looked by the nations involved in Euroskepticism. This examination was grounded in all the overlaps which are involved in the concepts of Euroscepticism and right wing populism. The administration of various organizations is eager to put resources into the progress of new contacts with parties operating in the European Region. This examination, however, just explores the concepts under Euro Scepticism and Right Wing Populism.

\subsection{Research philosophy}

Research philosophy is relying upon the advancement of new contentions and outcomes since it features the connection between the factors. Investigation of Ramirez et al., (2015) shows that research philosophy is measured as a significant key with regards to evaluating the job of various individuals in the study. Furthermore, Ramirez et al., (2015), there are numerous types of research philosophies, divided into quantitative and qualitative research philosophies. This study utilizes qualitative research theory since it is subjective in nature. Besides, this study will utilize a qualitative methodology, which is realism. The realism method relies upon the evaluation of genuine contentions and upheld with genuine insights and basic methodology.

The realism approach is more divided into two unique strategies known as critical realism and direct realism approach but this examination utilizes the critical realism approach since this examination depends on qualitative strategies for study (Attia and Edge (2017). With the assistance of the critical realism approach, the facts and figures of Euro Scepticism and Right Wing Populism parties are explored.. The suggestions featured will be fundamentally assessed to guarantee that Euro Scepticism and Right Wing Populism parties operating in the European Region should take. Dumay and Cai (2015) contended that individuals of various professions would gain proficiency with the suggestions, which can result because of the outcomes. Along these lines, for these sorts of examinations, critical realism approach is suggested in light of the fact that most of the people are not aware of these facts and figures.

\subsection{Measures}

Measures in a study permit understanding the valid and legitimacy measures used for the examinations. Safety measures ought to be embraced in each examination since it validates the research outcomes (Kumar 2019). In this examination, a few measures were included to increase the validity and legitimacy of the research discoveries, since it permits in assessing the most pertinent claims and arguments in an examination. Research 
articles after 2015 were chosen for critical surveys since they are considered the most current and pertinent research articles for exhibiting the arguments. Another significant measure required for the growth of arguments was additionally attempted by choosing the articles from Google Scholar site.

As indicated by Dumay and Cai (2015), Google Scholar site is viewed as one of the most significant forums, while choosing the articles for any critical survey. It is the duty of the investigator to guarantee that every one of the assets chose for the survey pursues the goals presented and does not get off the theme. Subsequently, this examination just chose research articles, which pursued at least one of the goals under the survey. Besides, this examination utilizes every one of the assets accessible for the examination by applying keyword strategy. In each chose article for this survey, the keywords of Euro Scepticism and Right Wing Populism were searched. Also, in excess of 10 articles were drawn from Google Scholar site to guarantee that discussion is provided in-depth. These were the few measures used for examination.

\subsection{Procedure}

So as to gather information, this study built up certain means to pursue and guarantee that everything stays on its line. This study created and followed five steps for examination. During the initial step, study goals were accumulated to guarantee that every one of the study goals stays with the theme. While the subsequent step included searching for insightful articles on Google Scholar. The third step included examination by investigating the contentions conveyed by the researchers for clarification of these connections among parties operating in the European Region. While in the fourth step, information was assembled by choosing the best contentions for the literature review. While in the last stage, literature review was composed and checked for blunders before finishing.

\subsection{Data collection method}

The data collection method is found as the most significant segment in a research paper procedure since it distinguishes the apparatuses or tools used for examination. The data collection techniques are divided into qualitative and quantitative methodologies, since the two of them embrace various strategies for examination (Snyder 2019).

This study utilizes the only qualitative techniques, which incorporate the collection of information from Google Scholar site. The strategies for examination incorporate choice of the articles for literature review. A quantitative methodology was not selected as individuals do not know about genuine realities of the concepts involved among parties operating in the European Region. Along these lines, legitimacy and validity examination would have gone down.

\subsection{Data analysis methods}

Data analysis methods are too differentiated into qualitative and quantitative techniques, and since this examination is using qualitative strategy, the qualitative strategy is chosen for examination. However, if a researcher is choosing research strategies by a critical assessment of the objectives and goals, it gets hard to make the choice of the techniques by appropriately choosing them (Ryder et al., (2019).

This examination utilizes a qualitative data analysis method as it is a literature review approach. By utilizing this subjective technique, this study assesses the explanations for the relationship forming of parties operating in the European Region.

\subsection{Sample size, sampling method, and population}

The sample size of an examination relies upon the choice of the articles through basic assessment of the populace and recognizing the correct sample for examination. Both probability and non-probability sampling can be used to choose the sample size since it is viewed as one of the most credible sources of examination (Ramirez et al., 2015). This investigation utilizes a purposive sampling strategy since it is taken as one of those procedures, which assists in choosing the best research sample by pursuing the motivation behind an examination. This study utilizes purposive sampling technique since it chose the research-based articles by investigating which one of them is talking about point of this examination. The sample size of this examination was 10-15 articles chose inside the most recent 5 years for evaluating the literature.

\section{Data analysis}

This chapter is divided into two sections. The first part of the chapter provides the understanding of overlaps in the concepts of Euro Scepticism and Right Wing Populism, while the second part of the chapter provides the understanding of different parties in both the domains.

\subsection{Euro Scepticism and Right Wing Populism - overlapping concepts}

According to scholars, populism is considered an elusive concept. The first task is considered a sharp cut as 
possible. While under the line of parsimonious approach, populism is called as the one depending on the two components. The concepts of right wing populism are depending on the two components, which are anti-elitism and people-centrism (Stengel, MacDonald and Nabers 2019). One thread in the literature suggests that right wing populism should considered as an ideological concept, while the second author (Evans and Mellon 2019) states that this concept cannot offer full answers to ideological concepts. Therefore, there is a critic that full ideologies are definitely striving to do so. Hence, there are many arguments presented against populism which show that it cannot be considered an ideal concept.

With respect to characteristics, there is a consensus which depends on two core components of populism, with reference to the people, and goes along with anti-elite and anti-establishment attitude. In an investigation presented by Rathbun (2018), it is argued that populism depends on two core concepts, which includes thinking about the people and bringing elite people together for meeting the collaborative environment between them. However, Kneuer (2019) argued that communicative strategy in this domain is very weak because it is constantly being revised by the parties. Supporting the argument, Corbett (2016) wrote that populism is consisting of minimal and necessary components which are based on anti-elitism and people-centrism. Hence, it is observed that conflicting statements and arguments have been reported in the concepts of both Euro Scepticism and Right Wing Populism.

When literature was searched, it was observed that there are mainly two components for populism, which depend on its several characteristics. Rathbun (2018) argued that populism is depending on explaining possible threat for society, however, what populists of right wing are including in their set of ideas comprise of ideas, which lead to movement of parties and their developments. Supporting the argument, Kneuer (2019) stated that populist take this concrete concern, and also thematise it. But this leads to disclosure of corruption and sometimes economic downturn. In addition, many studies of populism have emphasised on the occurrence of populism in generic forms, without going into details. Therefore, there is a need for identifying the roles of new changes, which are changing at a rapid pace.

If positions of right populist are looked upon, it is observed that European Crisis has mainly taken place due to globalisation issues, and following anti-EU approach. Kneuer (2019) said that both Euro Scepticism and Right Wing Populism people now believe on liberal value orientation, however, at the same time, European position shows a clear shift towards less Cosmo political claims. While, Corbett (2016) argued that ideological backgrounds of both Euro Scepticism and Right Wing Populism significantly differs, in terms of ideological poles and Euroscepticism concepts. Therefore, Right Wing Populism is not only focusing on ideological axis but also on the people centrism and anti-elitism approaches (Kneuer 2019; Corbett 2016). However, the integration of demarcation conflict is definitely influencing cross-cutting of the ideological axes.

\subsection{Analysis: populist and Eurosceptic parties in the context of the European crises}

In answer to this question, there are many sub-questions, which have been developed to answer this question:

1. Which crisis left which effect on Euro Scepticism and Right Wing Populism?

2. What are the different effects left because of those two crisis namely debt and refugee crisis?

3. Did the Euro Scepticism and Right Wing Populist parties benefit from that situation?

In order to answer these questions, the landscape of existing populist parties was reviewed by segmenting them into three groups, which include:

1. Older populist parties, which were existing before the crisis.

2. Old populist parties and euro scepticism parties already existing before the crisis with marginal support.

3. Parties which emerged within the context of at least one crisis situation and went against the voters' support.

3.2.1. The effects of the debt crisis on Euro Scepticism and Right Wing Populism parties

Regarding the first group of parties, it is observed that relevant and old populist parties have shown quite ambivalent results. According to the research article of Corbett (2016), the challenges were faced by many companies, when they wanted to remove the problems of debt crisis. Out of the 26 parties, only 8 were able to benefit from the debt crisis. Supporting the statement, one of the famous organisations named the Dutch PVV which was led by Geert Wilders was one of the most important cases. According to Corbett (2016), this organisation could have registered a considerable gain in 2010, and it lost half of what it could have gained after 2 years.

Although recent elections in 2017 were argued to show more gains and popularity before the elections, the level of support felt short just two days before. For example, Lees (2018) reported that the polling shows that refugee crisis has shown a significant rise in support because of a $30 \%$ increase in support of elections at the start of 2017, still strongest party PVV was not named as the best party. It is further stated that the gains made by PVV were quite small, as compared to the prognosis (Arzheimer 2015). While, the income made by FIDESZ is also an interesting case, because it gained $10 \%$ in 2010, and losing everything in 2017. It is also believed that most of the elder populist parties did not benefit from the debt crisis. For example, Arzheimer (2015) reported 
that most of the parties of Euro Scepticism and Right Wing Populism belonging to Denmark, Italy, Switzerland, Norway, Belgium and Germany lost many votes in the election.

While in Central Eastern Europe (CEE), some parties even disappeared due to lack of votes, which is very unusual. As one of the left wing parties named Latvian PCTVL resp, and LKS could have benefited which did not take place (Van Elsas, Hakhverdian and Van der Brug (2016). Therefore, these were some of the effects noticed by the parties due to the debt crisis

\subsubsection{The influence of refugee crisis on Euro Scepticism and Right Wing Populism parties}

The data with respect to this crisis was not readily available hence the results cannot be presented easily and equally as compared to debt crisis. According to the research findings of Van Elsas, Hakhverdian and Van der Brug (2016), within the first group of both Euro Scepticism and Right Wing Populism parties; it has been observed that only 7 of them were able to gain votes, which were in benefit. When comparison was carried out with those parties, the People's party of Euro-scepticism stood out of the others. It received an increase of $14 \%$, during this campaign, because it had a major supporting party with itself. However, the Populist Party headed by Sinn Fein did not perform to expectations, and in 2015, they lost a significant vote scale (Pirro, Taggart and van Kessel 2018). It is really astonishing to see that these parties lost a significant number of votes when these elections took place. Therefore, they could not benefit from refugee crisis, hence echoing these results.

If the arguments are further explored, the UKIP (euro-sceptic) party saw an increase of $8.5 \%$ in votes, hence benefiting from this situation. According to the findings of Plaza-Colorado, Gomez-Reino and Marcos-Marne (2018), this shows that support for euro-scepticism severely decreased, except for a few organisation. In addition, the performance of other parties in Euro Scepticism and Right Wing Populism domain showed emergence of only a few parties. Most of those parties already emerged as successor in the development of new domain due to which the performance of each company changed with the passage of time. However, Dostal (2015) argued that this was not the case in other Euro Scepticism and Right Wing Populism parties, which included $\mathrm{AfD}$, which in contrast successfully explained the underlying cultural sentiments. Based on the arguments they concluded that most of the parties emerged as some of them lost in last election because people now understand that they are being flirted by the government.

\section{Discussion and Conclusion}

The first question of this article was based on the crisis, which was faced by both Euro Scepticism and Right Wing Populism parties. A very limited data were available in this domain, which showed overall lacking performance of Euro Scepticism and Right Wing Populism parties (Dostal 2015; Gifford 2015). Therefore, it can be concluded that the economic crisis, brought benefits for some older and established populist parties. Most of them were unable to gain support during the debt crisis because some old parties of both Euro Scepticism and Right Wing Populism lost their precious votes.

Some scholars argued that the results obtained in the elections are not under control and the management of different organisations was unable to monitor them. In an investigation presented by Petsinis (2019), it was argued that the results obtained by the management of different organisations showed that they were not obtaining the results. The analysis confirmed that two European crisis resulted in the development of low support for both Euro Scepticism and Right Wing Populism parties. Still, there was an emergence of new populist parties, which was mainly influenced by debt crisis. This showed that voters of both these parties are now feeling sensitive as to whether they both have right agenda. In addition, both these parties suffered from heavy criticism, when they tried to perform activities, because heavy protests were observed in Italy and Spain. All the criticism was given on an argument that both Euro Scepticism and Right Wing Populism carry out illegal activities and corrupt practices.

Based on the findings of this article, it can be concluded that recent studies have emphasised on the fact that cultural factors are explanatory variables, which are now changing according to the changing trends in the nation. Furthermore, people do not want these parties to operate in their regions, because a new cleavage is running among pro-European and cosmopolitan orientation. The results also support the fact that the transnational cleavage is crosscutting the ideological axis. Especially, due to the emergence of new populist parties, it has been observed that they are covering not only left right wing, but also an undefined spectrum. However, all these parties significantly vary in terms of Eurosceptic orientation. However, we would like to say that results can be comprehended to a major extent because this study did not find relevant data in detail.

\section{Acknowledgements}

I firmly argue that this research was carried out by me, and I would like to acknowledge that my parents and friends helped me in completion of this article. 
References

Arzheimer, K. (2015). The afd: Finally a successful right-wing populist eurosceptic party for germany?. West European Politics, 38(3), 535-556.

Corbett, S. (2016). The social consequences of Brexit for the UK and Europe: Euroscepticism, populism, nationalism, and societal division. The International Journal of Social Quality, 6(1), 11-31.

Damiani, M., \& Viviani, L. (2019). Populism and Euroscepticism in Podemos and in the Five Star Movement. Faraway, so close?. Partecipazione e conflitto, 12(1), 197-216.

Dostal, J. M. (2015). The Pegida Movement and German Political Culture: Is Right-Wing Populism Here to Stay?. The Political Quarterly, 86(4), 523-531.

Evans, G., \& Mellon, J. (2019). Immigration, Euroscepticism, and the rise and fall of UKIP. Party Politics, 25(1), 76-87.

Gifford, C. (2015). Nationalism, populism and Anglo-British Euroscepticism. British Politics, 10(3), 362-366.

Hooghe, L., \& Marks, G. (2007). Sources of euroscepticism. Acta Politica, 42(2-3), 119-127.

Kneuer, M. (2019). The tandem of populism and Euroscepticism: a comparative perspective in the light of the European crises. Contemporary Social Science, 14(1), 26-42.

Lees, C. (2018). The 'Alternative for Germany': The rise of right-wing populism at the heart of Europe. Politics, 38(3), 295-310.

Odmalm, P., \& Rydgren, J. (2019). Introduction: comparing and reconceptualising the (populist) radical right. European Political Science, 18(3), 373-378.

Petsinis, V. (2019). Identity Politics and Right-Wing Populism in Estonia: The Case of EKRE. Nationalism and Ethnic Politics, 25(2), 211-230.

Pirro, A. L., Taggart, P., \& van Kessel, S. (2018). The populist politics of Euroscepticism in times of crisis: Comparative conclusions. Politics, 38(3), 378-390.

Plaza-Colodro, C., Gómez-Reino, M., \& Marcos-Marne, H. (2018). Does host ideology shape populist parties' attitudes towards the EU? The links of populism and Euroscepticism in Southern Europe. Revista Internacional de Sociología, 76(4), e112.

Rathbun, B. (2018). Populism fed pro-Leave sentiment, but what kind of populism?. LSE Brexit.

Shein, S. (2019). European Mainstream Parties' Strategies in Response to The Right-Wing Populism: The UK Case. Higher School of Economics Research Paper No. WP BRP, 67.

Stengel, F. A., MacDonald, D. B., \& Nabers, D. (2019). Conclusion: Populism, Foreign Policy, and World Politics. In Populism and World Politics (pp. 365-372). Palgrave Macmillan, Cham.

Van Elsas, E. J., Hakhverdian, A., \& Van der Brug, W. (2016). United against a common foe? The nature and origins of Euroscepticism among left-wing and right-wing citizens. West European Politics, 39(6), 11811204. 